slightly different; while the values for the elastic force of vapour have not been corrected for the assumed barometric pressure. Nevertheless, a decidedly rapid increase in the humidity of the atmosphere is shown, and in considering the table, it must be borne in mind that the results, if reduced to a mean temperature, would be even more striking.

Barnet, February 18. E. V. WINDSOR.

\section{Lagrange's Equations.}

As most of the standard treatises on dynamics contain satisfactory proofs of Lagrange's equations, I do not see that any useful purpose is served by proposing an additional one. The important point is this:-That amongst the rumerous forms in which the kinetic energy of a dynamical system can be expressed, there is only one form which can be employed in using Lagrange's equations, and that is the Lagrangian form in which $\mathrm{T}$ is expressed as an $n$-ary quadric of velocities which are the time variations of the coordinates.

Similarly in using Hamilton's equations

$$
\begin{aligned}
\frac{d \Theta}{d t}+\frac{\partial}{\partial \theta}(\pi+\mathrm{V}) & =0 \\
\frac{\partial \pi}{\partial \theta} & =\dot{\theta},
\end{aligned}
$$

there is only one form, viz. the Hamiltonian form, which it is permissible to use in which $\mathbb{C}$ is expressed as an $n$-ary quadric of momenta of the same type as the coordinates of the system. Now the form $\frac{1}{2}\left(\mathrm{~A} \omega_{1}^{2}+\mathrm{B}_{2}^{2}+\mathrm{C}_{3}^{2}\right)$ is neither Lagrangian nor Hamiltonian, and therefore cannot be used in either equations.

Fledborough Hall, Holyport, Berks, March 6 . A. B. BASSET.

\section{A Remarkable Meteor.}

I SEND an account of a meteor, to me remarkable because of its extremely slow movement and also because of its apparently reaching the surface of the earth, a little east of north-east of here. The "falling star "was about equal in brightness to Sirius. When first it attracted my attention it would be just below the cluster "Coma Berenices." So slowly was it falling that I first mistook it for the fixed star Arcturus, the resemblance being probably increased by its colour, which was reddish. It slowly dropped vertically downwards, its brilliancy keeping constant; it left no trail. Its line of descent would make a small angle with the line $\delta \beta$ Leonis. I watched it fall right to ground-but it may not have quite reached earth, as there was a rise in the ground before me. About one-third of its distance from the ground it appeared to "wobble, "but that may have been an illusion. It fell so slowly as to take quite five seconds. The time was about $7.22 \mathrm{p.m}$. on March 15 , when I was a little more than a mile to the south of Basingstoke.

J. E. C. LIDDLE.

Fairfields, Basingstoke, Hants.

\section{Dawn of Modern Geography.}

IN the review of my book ("Dawn of Modern Geography," vol. ii.) which appeared in NaTuRE, November 27 , 1902 , it is stated (p. 75), by way of repetition from NATURE's review of vol. $i$. of the same work, that the "revision of the whole of chapter vi. of vol. i., on geographical theory, together with Mr. Beazley's account of the history and use of mediæval maps for the whole book," was "due to $\mathrm{Mr}$. C. H. Coote, of the Map Department of the British Museum." When this unfounded assertion was first made, I wrote (with the entire concurrence of Mr. Coote) and pointed out to the reviewer that he was mistaken. As the misleading statement now reappears, I may say that $\mathrm{Mr}$. Coote never saw a line of the "Dawn of Modern Geography," vol. i.--nor had I any consultation with him on any point therein---until after the last corrections of proof had been made, and the sheets finallv returned for press.

C. RaymoNo BEazI.FX.

\section{Nernst Lamps in Lanterns.}

I T was suggested to me by a friend to use a Nernst lamp in a lantern. On trying the experiment I have found that a one ampere 220 volts Nernst lamp gives quite a fair result in a small lantern, certainly very much better than could be got with oil wicks, and when put at a small angle from the horizontal the filament gives a very concentrated light. For lantern purposes it would be quite possible to remove the heating coil and to start the lamp by means of an alcohol flame. Indeed, I think that a special Nernst burner could be made for lanterns, giving a high candle power and fitted with a suitable fitting, which would largely replace limelight, and it would even in many cases replace the are lamp where a powerful light was not required. There can be no doubt whatever about its convenience.

C. Turnbuli.

Electricity Works, North Shields, March 16

\section{PHOTOGRAPHS OF VOLCANIC PHENOMENA. ${ }^{1}$}

THE application of photagraphy to the recording and illustrating of volcanic phenomena has done much to secure accuracy, and the avoidance of those sources of error to which the students of these stupendous outbursts must always be particularly liable. Valuable as are the drawings made under the superintendence of Sir William Hamilton for his classic work, "Campi Phelgræi," they do not carry the conviction to the mind of a reader of the work that actual photographs would do; while many of the drawings of volcanic phenomena in less carefully illustrated works are faulty and exaggerated almost to grotesqueness.

Perhaps the first serious attempts to show the features of a volcanic outburst by means of instantaneous photography were those made by an enterprising photographer of Naples, during the Vesuvian eruption of 1872 . He obtained three photographs at different hours, which illustrate very clearly the scale, the principal details and the changes of phase in the outburst. These photographs have since been reproduced in many geological treatises.

During the visit of the Geologists' Association to the South Italian volcanoes in 1890 , a number of photographs were obtained by members of the party which demonstrated the value of instantaneous pho'ography in recording all the successive stages of an outburst. Some of these photographs were reproduced in a memoir published by Dr. Johnston Lavis at Naples in $\mathrm{r} 8 \mathrm{gr}$.

Dr. Tempest Anderson's contributions to the subject appear to have begun in $188_{5}$, when he read a paper, illustrated by admirable photographs, before the Geological Section of the British Association at Aberdeen. This paper dealt specially with the extinct volcanoes of Auvergne. In subsequent years, Dr. Tempest Anderson has visited almost all accessible volcanic districts--Italy and Sicily, the Canaries, Iceland, and various parts of the North American Continent. Last year he volunteered, at his own expense, to join the expedition sent out by the Royal Society to report on the eruptions of St. Vincent and Martinique, and the results obtained by Dr. Flett and himself have just been published in the Transactions of the Royal Society.

The work before us consists of reproductions by

1 "Volcanic Studies in Manv Lands: heing Reproductions of Photographs by the Author of above One Hundred Actual Objects, with Explanatory Notices." By Jempest Anderson, M.D., B.Sc. Lond. Y orkshire philosophical Societv (London: John Murray, rgo3.) Price 2is. net. 
means of half-tint blocks, for the most part of a very clear and satisfactory character, of photographs taken by the author. Each plate is accompanied by a letterpress description, calling attention to the principal phenomena which are illustrated in the plate. In a short introduction upon "Photographic Methods," the author gives a number of valuable hints, which cannot fail to be of service to every geologist who wishes to go abroad armed with the camera. Dr. Tempest Anderson's remarks on the lenses to be employed, on the importance of the use of a firm stand, and on the relative advantage of plates and films, should be read by everyone desirous of doing good work in this direction.

Of the photographs reproduced in the 105 plates of this volume, seventeen are taken from Vesuvius and the surrounding country, two from Etna, eight from the Lipari Islands, eleven from the Auvergne and Central

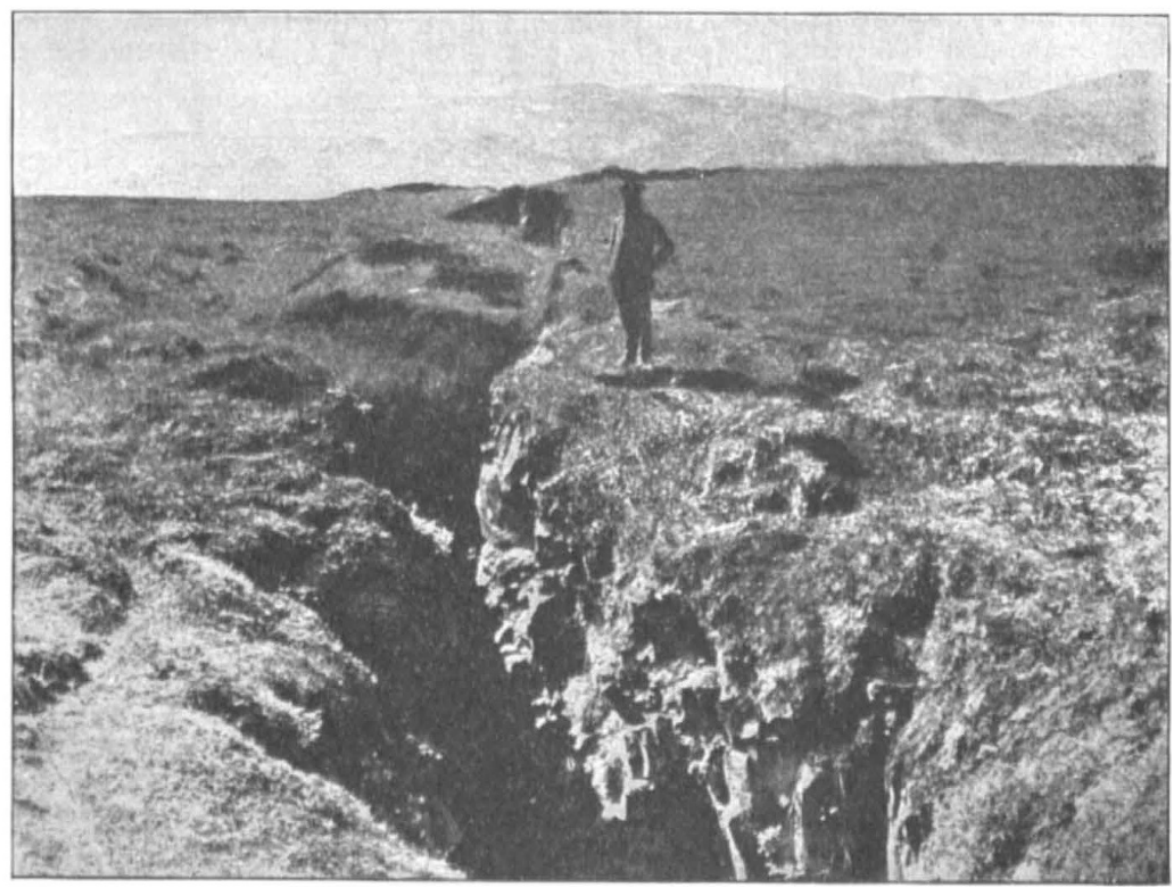

Fig r.-A Gáj (pronoun (Gesw), Reykjanes Peninsula, Iceland.

France, eight from the Canaries, thirty-two from Iceland, five from the Eifel and Central Germany, eight from the Yellowstone Park and other parts of the Western Territories of North America, ten from various ancient volcanic districts in the British Isles, and four from the West Indies.

Most of the pictures are wider than the page of NATURE, but the one here reproduced will give a good idea of their general character. Those who have seen reproductions as lantern-slides of these pholographs thrown in an enlarged form upon a screen can testify to their excellence and value. The fact that in many cases-motably in Iceland and the West Indies-the work has had to be carried on under most unfavourable conditions, while it increases our admiration for the skill and perseverance of the author, cannot but greatly enhance the value of the results obtained. 'The author of this work is to be congratulated upon having discovered a field of work in which he is able to make such valuable contributions to science.

$$
\text { NO. } 1742 \text {, voL. } 67]
$$

\section{THE AFTERMATH OF THE PARIS EXHIBITION.}

CHE size and importance of the Paris Exhibition of 1900 is beginning to be appreciated in its true significance. Many who visited the exhibition in a casual way were greatly impressed with its vastness. and came away with the feeling that the exhibition was a marvellous illustration of the Frenchman's power of organisation; but that, owing to its very immensity, it lost much of its practical value. The aftermath of the exhibition is still with us, and we begin to seefrom the number of special reports upon the different departments - that although not a financial success, the exhibition has left its mark upon commerce and science in a way that bids fair to rival, in its economic results, the immense advantages that accrued to this country from the Great Exhibition of $185 \mathrm{I}$, and justly to warrant the enormous labour put forth in its inception and organisation.

In the Revue générale des Sciences (November, 1902) Prof. A. Haller, of the Paris University, contributes the first part of a most interesting and suggestive article upon the "Chemical and Pharmaceutical Industries " at the Paris Exhibition. He commences with a reference to the retrospective stand, where apparatus and substances of historiçal interest were exhibited. Amongst these exhibits were specimens of aluminium as prepared by Wöhler, sulphuric anhydride by Winckler, the first specimen of magnesium which was prepared electrolytically by Bunsen, and many other products and apparatus of historical interest. $\mathrm{He}$ then goes on to refer to artificial substances such as ultramarine, synthetical perfumes, pharmaceutical preparations and a very complete collection of coal-tar dyes.

The article is mainly devoted to the German chemical industries, and by far the most interesting paragraphs are those in which Prof. Haller reviews the great advance in German science, and endeavours to assign a reason for this phenomenal development. En passant, he regrets that Great Britain did not see her way to send apparatus and specimens of historical interest, which she, who can boast of the great names of Priestley, Cavendish, Davy and Faraday, might so easily have done.

The recent trade depression in Germany has attracted considerable attention, but although many branches of industry have been passing through a period of great difficulty, and the total German exports for rgor showed a decrease of 240 million marks, the exports of the chemical trade showed an increase of ro million marks. Prof. Haller attributes much of the success of the Germans in the chemical trade to the management and to the employment of men of high scientific 